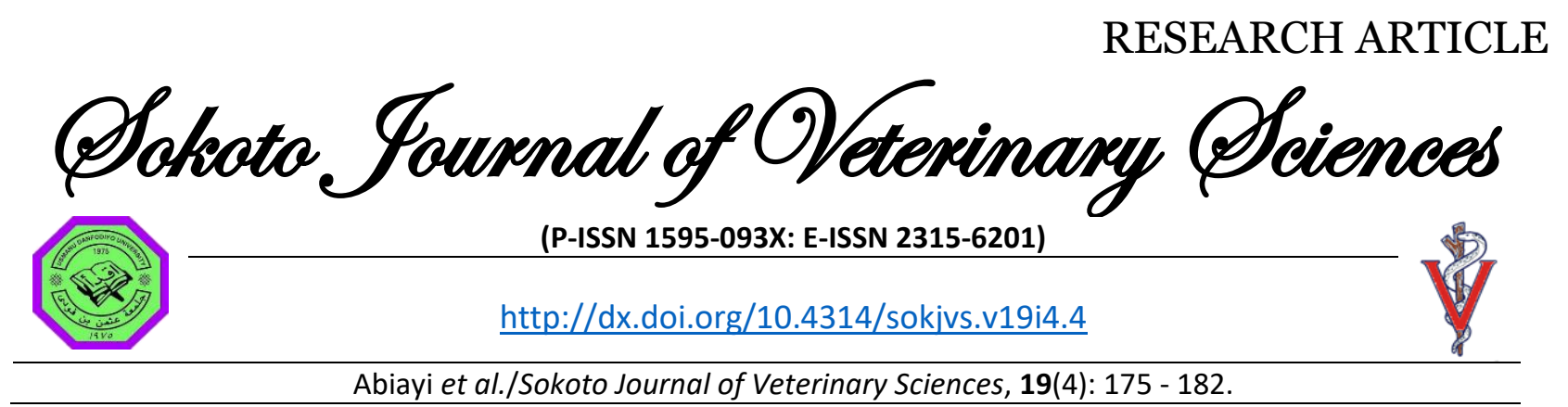

\title{
Serological evidence of influenza A/H9 in indigenous birds and level of awareness at live bird markets, Plateau State
}

\author{
DC Abiayi ${ }^{1 *}$, GR Otolorin ${ }^{1}$, AA Dzikwi-Emennaa ${ }^{1} \&$ CA Meseko ${ }^{1,2}$ \\ 1.Department of Veterinary Public Health \& Preventive Medicine, Faculty of Veterinary Medicine, University of Jos, \\ Plateau State, Nigeria \\ 2.Animal Influenza Division, Infectious and Transboundary Animal Diseases, National Veterinary Research Institute, \\ NVRI, Vom, Plateau State, Nigeria
}

*Correspondence: Tel.: + 2348137893754; E-mail: davidabiayi@gmail.com

\begin{abstract}
Copyright: (c) 2021
Abiayi et al. This is an open-access article published under the terms of the Creative Commons Attribution License which permits unrestricted use, distribution, and reproduction in any medium, provided the original author and source are credited.
\end{abstract}

Publication History: Received: 20-05-2021 Revised: 03-08-2021 Accepted: 12-08-2021

\begin{abstract}
Avian influenza is a zoonotic disease that can adversely affect humans and animals. Nigeria first reported an outbreak of avian influenza which was caused by subtype H5N1 in 2006, thereafter virological and serological surveys revealed the importance of local birds in live bird markets and the community at large in the epidemiology of avian influenza in the country. In the present study, 276 serum samples were collected for serological testing over five months from apparently healthy local birds in live bird markets within two Local Government Areas of Plateau State, to determine antibody prevalence to avian influenza $A$ virus. The detection of influenza $A$ antibody was carried out using an Enzyme-linked immunosorbent assay and further tested by haemagglutination inhibition to determine the specific serotype of the influenza $A$ virus. The result showed a prevalence of $30.4 \%(n=84)$ of antibody to influenza A, 26\% $(n=72)$ of serotype $\mathrm{H} 9,1.4 \%(n=4)$ of serotype $H 7$, and none was confirmed to be $\mathrm{H} 5$ serotype. Comparatively, Jos-North had a lower relative risk with a prevalence of $18.9 \%(n=18)$ to the disease as compared to Jos-South with a prevalence of $36.5 \%$ ( $n=66)$. This study showed the presence of low pathogenic avian influenza $A$ virus in live bird markets within the study area with the dominance of antibodies to H9. To our knowledge, this is the first serological indication of serotype $\mathrm{H} 9$ in Plateau State and Nigeria. Evidence of influenza $\mathrm{A} / \mathrm{H} 9$ in an ecological niche known for the circulation of subtypes $\mathrm{H} 5 \mathrm{Nx}$ may complicate the epidemiology and control of avian influenza in the region and Nigeria at large. The level of awareness by the live bird market operators about avian influenza (Al) was relatively low as indicated by the questionnaire survey conducted. Live bird market operators and poultry farmers need to maintain a high level of biosecurity and limit mixing local birds with commercial poultry to prevent the transmission of the virus which may have adverse effects on poultry production, national and international trade, the economy and public health.
\end{abstract}

Keywords: Avian influenza; Jos Nigeria; Live bird market; Serological evidence; Serotype H9 


\section{Introduction}

Avian influenza (Al) is a highly infectious disease caused by type $A$ influenza viruses. This virus belongs to the family Orthomyxoviridae which are singlestranded 8-segmented negative sensed RNA that encode at least 10 viral proteins (Machalaba et al., 2015; Bevins et al., 2016). The disease constitutes a major threat to the poultry industry worldwide (Meseko \& Oluwayelu, 2019). The Orthomyxoviridae family is divided into four main genera viz; A, B, C, D and two other genera found in fish and arthropod (Payne, 2017). Avian influenza belongs to the genus of influenza A which is the most widespread among other influenza viruses with members infecting avian and mammalian species (Thomas et al., 2019). Influenza A viruses are further classified by subtypes based on the glycoproteins, haemagglutinin (HA) and neuraminidase (NA) proteins. Presently, there are 18 subtypes and 10NA subtypes (Kumar et al., 2018; Tindale et al., 2020). Divergent avian influenza A viruses $\mathrm{HA} \mathrm{H} 17, \mathrm{H} 18$, and NA N10 are recently isolated from bats (Lamb \& Roberts, 2014: Oluwayelu et al., 2015: Akanbi et al., 2016a). Only H1, H2 and H3 are commonly found in humans but viruses with $\mathrm{H} 5, \mathrm{H} 7$ and $\mathrm{H} 10 \mathrm{HA}$ have been isolated from humans but without extensive human to human transmission of the viruses (Lamb et al., 2014). The HA and NA are capable of eliciting subtype-specific immune responses which protect within subtypes and partially protect across subtypes (Tindale et al., 2020).

The influenza A viruses infect humans and many different animals, the virus can also evolve into new subtypes of influenza A virus which may have the ability to infect humans and have a sustained human to human transmission, which can cause an influenza pandemic (Markets et al., 2020; Steensels et al., 2020). However, certain subtypes of influenza A virus are specific to certain species, except waterfowls, which are host to all known subtypes of influenza $A$ viruses (Meseko et al., 2020).

The primary mode of transmission in human cases of avian influenza virus infection is from bird to human through direct or close contact with infected birds or contaminated surfaces (Meseko \& Oluwayelu, 2019). Even though some studies have shown the prevalence of various strains and subtypes of Avian influenza antibodies in the serum of apparently healthy birds in live bird markets in some parts of the country (Meseko et al., 2018b), there is a dearth of this information in many other parts of the country, including Plateau State.

This research aims to detect antibodies to the avian influenza $A$ virus in local birds, at LBMs in Jos-north and south, Plateau State, Nigeria using enzyme-linked immunosorbent assay, and haemagglutination inhibition test. Knowledge of the seroprevalence of avian influenza in Jos, Plateau State will support public health workers with relevant data that will help in the planning of Avian Influenza control programmes at the human-animal interface in these areas.

\section{Materials and Methods Study area}

Jos city with coordinates $9.8965^{\circ} \mathrm{N}, 8.8583^{\circ} \mathrm{E}$ is in Plateau State, which is in the middle belt of Nigeria, Plateau is situated in the tropical zone of Nigeria, at a higher altitude resulting in a near temperate climate with an average temperature of between 13 and $22^{\circ} \mathrm{C}$. Harmattan winds bring about the coldest weather between December and February. The warmest temperatures usually occur in the dry season in March and April. The mean annual rainfall varies between $131.75 \mathrm{~cm}$ (52 in) in the southern part to $146 \mathrm{~cm}$ (57 in) on the Plateau. Although the state is best known for its mining production, agriculture is the major occupation of the people. It is the administrative capital and largest city in Plateau State and has a major concentration of poultry farms in Nigeria (Akkermans et al., 2015; Chinyere et al., 2020). Poultry farmers on the Plateau, practice either the deep litter system or the battery cage system of management, while a mixed management system is practised at live bird markets. This study was conducted in Jos-North and Jos-South Local Government Area of Plateau State, Nigeria. In Jos North, two major live bird markets (LBMs) are known, which are; Chobe LBM with coordinates 9055'59"N and $8052^{\prime} 55^{\prime \prime} \mathrm{E}$ and Kasuwan Kaji LBM with coordinates 9056'12"N and 8953'15"E. Jos-South houses two major LBM which includes Kwararafa LBM in Bukuru with coordinates 9047'20" N and 851'52" $\mathrm{E}$ and LBM at "British America" close to the Jos abattoir with coordinates $9^{\circ} 53^{\prime} 39^{\prime \prime} \mathrm{N}$ and $8^{\circ} 53^{\prime} 18^{\prime \prime} \mathrm{E}$.

\section{Study design}

A cross-sectional study was carried out to detect the presence of avian influenza antibodies in mixed species of indigenous birds within the study area. A pretested questionnaire was also used to obtain information about avian influenza from live bird markets operators in the study area.

Determination of sample size

The sample size for the study was determined using the formula by Cohen (1988): 
$\mathrm{N}=\mathrm{Z}^{2} \mathrm{Pq} / \mathrm{L}^{2}$

Where:

$\mathrm{N}=$ Number of samples to be taken from a population

$\mathrm{Z}=\mathrm{Z}$-score (for a two-tailed test at $95 \%$ confidence interval) $=1.96$

$\mathrm{P}=$ Prevalence of $\mathrm{Al}$ antibodies $=18.7 \%$ (Ameji et al., 2017)

$q=1-P=1-0.187=0.813$

$\mathrm{L}=$ a measure of the confidence interval = allowable error $(5 \%)=0.05$.

Substituting the values into Cohen's formula gives.

$\mathrm{N}=\left(1.96^{2} \times 0.187 \times 0.813\right) / 0.5 \%=233.6$

$\mathrm{N}=234$.

The sample size was increased to 276 to reduce sampling error.

\section{Questionnaire}

Validity and reliability of the questionnaire: The questionnaires were validated by experts in National Veterinary Research Institute and evaluated before testing for validity. The reliability and validity index expected was calculated using Karl Pearson"s coefficient of correlation; the same one that was used to test the overall data validity.

Cronbach's alpha (coefficient alpha) method of estimating reliability was used to estimate the reliability of the test. It was found to be 0.96 . To make sure the questionnaire was free from vague and unclear items, the draft questionnaire was examined by advisors and by experts on the area for comment. The questionnaire was for the marketers. It was carefully constructed as it was the heart of the study. The researchers developed them from scratch with the help of professionals as supervisors in the final stage of their development. To ensure that the questionnaires captured data accurately, the wordings were carefully constructed to avoid ambiguity.

\section{Sampling and sample collection}

Blood samples were collected from local birds after proper restraint to expose the area over the wing vein. A 21-gauge needle and $5 \mathrm{~mL}$ syringe were used to obtain $2 \mathrm{~mL}$ of blood from the wing vein. A total of 276 blood samples were collected over 5 months (March to July 2020) from apparently healthy local birds at live bird markets in the Local Government Areas in Plateau State as indicated by Figure 2. A total of 24 blood samples were collected from Kasuwan Kaji in Jos-North, 71 blood samples were collected from Chobe LBM in Jos-North, 19 blood samples were collected from "British American" LBM Jos-North and 162 blood samples were collected from Kwararafa
LBM in Jos-south. The collected blood was allowed to stand for two hours for clotting to occur and the serum was decanted into a bijou bottle, stored under ice then transported to the Regional Laboratory for Animal Influenza and Other Transboundary Diseases of the National Veterinary Research Institute (NVRI) Vom within 24 hours. These were stored at $-20^{\circ} \mathrm{C}$ until used.

\section{Detection of avian influenza antibodies}

Detection of avian influenza antibodies by enzyme link immunosorbent assay (ELISA): Influenza A virus antibody ELISA Test Kit (IDEXX Influenza A, Hoofddorp, Netherland) was used for the detection of influenza A antibodies. This assay measures the relative level of antibodies to influenza $A$ in animal serum. The assay is performed on 96-well plates that have been pre-coated with influenza $A$ viral antigen. This procedure was carried out according to the OIE manual (2018).

The absorbance of the samples and controls were subsequently measured and recorded at $650 \mathrm{~nm}$.

Determination of specific serotype of influenza a virus from the collected samples using haemagglutination (HA) test and haemagglutination inhibition ( $\mathrm{HI})$ test: After ELISA was carried out, Positive samples were further analyzed by haemagglutination inhibition (HI) test for Al serotype-specific antibodies using a panel of reference antigens comprising $\mathrm{H} 5, \mathrm{H} 7$ and $\mathrm{H} 9$ viruses with four haemagglutination units of each antigen according to the OIE manual (2018).

\section{Results}

Questionnaire results

The findings from the questionnaire survey showed that $45 \%(45 / 100)$ of the respondents had heard about $\mathrm{Al}, 33 \%$ (33/100) comprehended what Al was; hence $39 \%$ of the respondents had heard about Al or knew what Al was, therefore 61\% (61/100) did not know about the disease.

However, Table 1 showed that only $39.5 \%$ of those knowledgeable about Al could identify some clinical signs associated with suspected cases of HPAI, amongst which were haemorrhagic wattle, decreasing egg production and unusual high mortality. Furthermore, $60 \%(60 / 100)$ of the respondents reported seeking veterinary intervention when their flocks showed symptoms of diseases, $20 \%(20 / 100)$ of the respondents reported that they sell their sick birds, while 25\% (25/100) reported that they slaughter for consumption and $70 \%(70 / 100)$ reported to attempt medicating the birds themselves before any other option. 
Table 1: Questionnaire Evaluation

\begin{tabular}{llll}
\hline S/N & Questions & Yes & No \\
\hline 1 & Have you heard about Avian Influenza (AI)? & 45 & 55 \\
2 & Do you know what Avian Influenza (AI) is? If NO go to Q4 & 33 & 67 \\
3 & & \\
& How many signs can you recognise? & 9 \\
& Sneezing & 30 & 30 \\
& Coughing & 9 & 24 \\
& Ocular discharges & 15 & 33 \\
Decreased egg production & 6 & 4 \\
Haemorrhagic wattles & 35 & 36 \\
Haemorrhagic feets & 3 & 37 \\
Haemorrhagic skin of the head & 2 & 34 \\
Swollen head & 5 & 21 \\
Pinpoint haemorrhage on the shank & 18 & 8 \\
High mortality & 31 & \\
What do you do when you observe any of the above signs in & & \\
Q3? & & 30 \\
Self medicate & 70 & 40 \\
Call/ Visit a Veterinary doctor & 60 & 75 \\
Slaughter and consume & 25 & 80 \\
\hline Sell off & 20 & \\
\hline
\end{tabular}

Table 2: Prevalence of A.I. Antibody In Local Chickens Sampled from Jos-North and Jos-South Local Government Area, Plateau State

\begin{tabular}{llllll}
\hline S/N & LGA & Number tested by ELISA & Number of positive (prevalence) & Number of negative & $\mathrm{Cl}$ \\
\hline 1 & Jos-North & 95 & $18(18.9 \%)$ & 77 & $11.9-28.6$ \\
2 & Jos-South & 181 & $66(36.5 \%)$ & 115 & $29.5-44.0$ \\
& Total & 276 & $84(30.4 \%)$ & 192 & $25.1-36.29$ \\
\hline
\end{tabular}

Table 3: Prevalence of A.I. Antibody among local chicken samples collected from the various LBMs within Jos North and South

\begin{tabular}{lllllll}
\hline S/N & LBMs & $\begin{array}{l}\text { Number tested by } \\
\text { ELISA }\end{array}$ & $\begin{array}{l}\text { Number of positive } \\
\text { (prevalence) }\end{array}$ & $\begin{array}{l}\text { Number of } \\
\text { negative }\end{array}$ & OP & $\mathrm{Cl}$ \\
\hline 1 & Kasuwan Kaji LBM & 24 & $5(20.8 \%)$ & 19 & 2.6125 & $9.2-40.3$ \\
2 & Chobe LBM & 71 & $13(18.3 \%)$ & 58 & 3.0673 & $10.5-29.6$ \\
3 & British America LBM & 19 & $0(0.0 \%)$ & 19 & - & $0.0-20.9$ \\
4 & Kwararafa LBM & 162 & $64(40.7 \%)$ & 96 & Ref & $33.2-48.8$ \\
& Total & 276 & 84 & 192 & & \\
\hline
\end{tabular}

\section{Serological test}

Enzyme-linked immunosorbent assay (ELISA): From the total of 276 serum samples tested for AIV, $18.9 \%$ (18/95) samples collected from Jos-North were positive to A.I. while $36.5 \%(66 / 181)$ samples collected from Jos-South were positive to A.I. The prevalence of AIV antibodies in the tested local chicken sera from the different live bird markets surveyed was $20.8 \%(5 / 24), 18.3 \%$ (13/71), $0.0 \%$ $(0 / 19)$ and $40.7 \%(66 / 162)$ for Kasuwan Kaji LBM, Chobe LBM, British America LBM and Kwararafa LBM respectively. The overall prevalence of avian influenza
A antibodies in the study areas was $30.4 \%$ (84/276). There were statistically significant differences within the LBMs (Tables 2, 3 and Figure 1).

Haemagglutination and haemagglutination inhibition test

From the Haemagglutination (HA) and haemagglutination inhibition $(\mathrm{HI})$ tests carried out to determine the specific serotype of the influenza $A$ virus from the ELISA-AIV positive samples in the study area, a total of $85.7 \%(72 / 84)$ of the positive samples were confirmed to be $\mathrm{H} 9$ serotype. A total of $4.8 \%$ (4/48) were confirmed to be $\mathrm{H} 7$ serotype; while 
$14.3 \%$ (12) of the AIV positive samples were neither positive for $\mathrm{H} 9$, $\mathrm{H} 7$ nor $\mathrm{H} 5$. This survey showed the possible coexistence and cocirculation of $\mathrm{H} 9$ and $\mathrm{H} 7$ serotypes of LPAI in the country because the four samples which tested positive to $\mathrm{H} 7$ all were positive to $\mathrm{H} 9$ and for the first time to our knowledge $\mathrm{H} 9$ serotype is detected from local birds in Plateau State.

\section{Discussion}

Avian influenza has its zoonotic potential as described by WHO (2019), but the market operators had a low level of awareness as indicated by the questionnaire survey conducted, which is believed to propagate the spread of the virus as they carry on with their daily activities, therefore awareness against avian influenza and its zoonotic potential must be created in LBMs and the community at large hence reducing the number of uninformed persons. The questionnaire also revealed that $60 \%$ of the respondents seek veterinary intervention when their birds are sick, which is the right choice to make and this should be encouraged within the society as it aids earlier identification of causative agents and reduces drug resistance caused by indiscriminate use of drugs, as the questionnaire revealed that $70 \%$ of the respondents attempt treatments themselves before any other options. The consumption and sale of sick birds should be discouraged in the society at large as these will hasten Jos-south

Red: Negative value

Blue: Positive value Government Areas

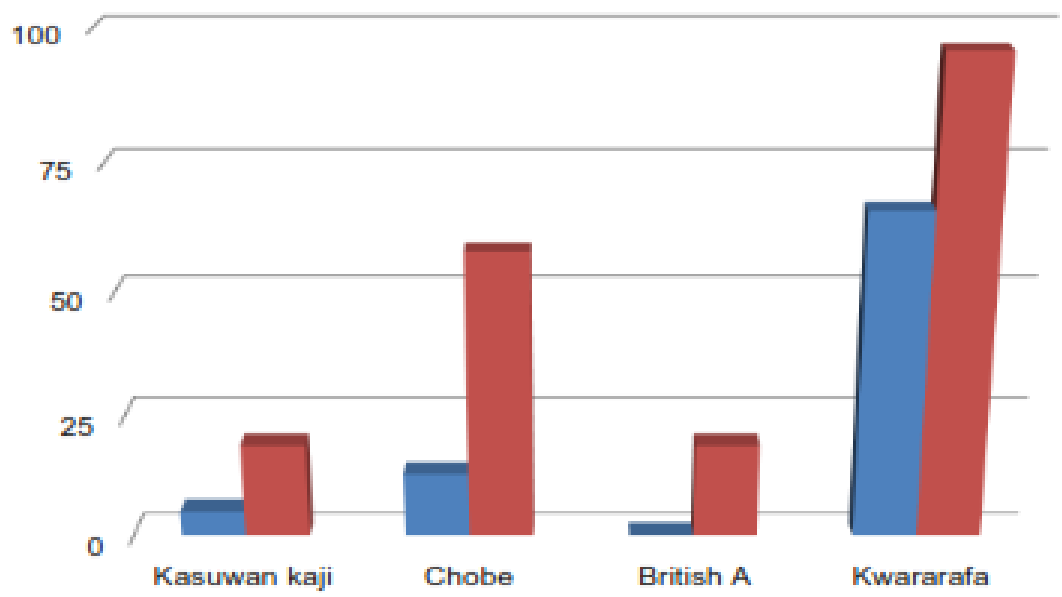

Figure 1: A graph showing the level of infection in each LBM within Jos-north and

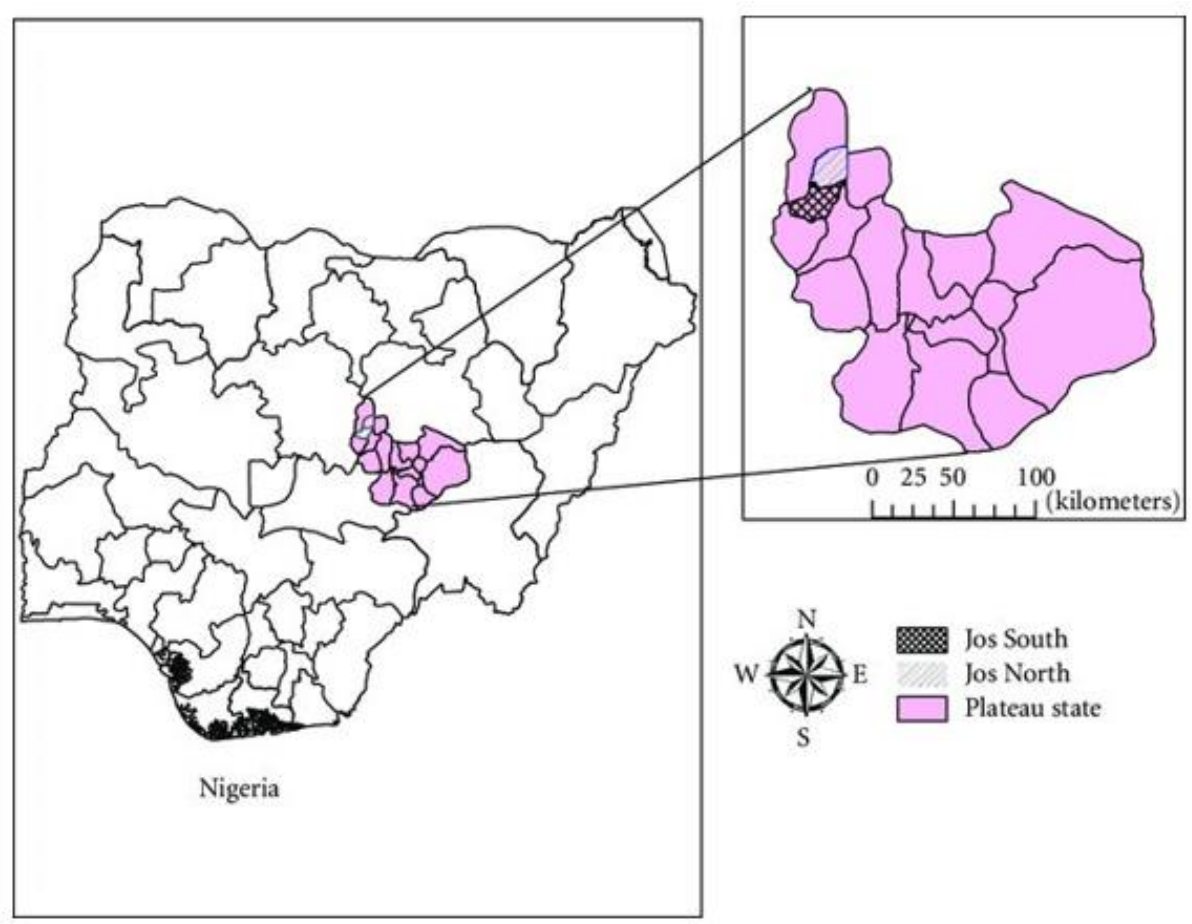

Figure 2: Map of Nigeria, showing Plateau state and Jos North and South Local

Source: Meseko et al. (2012) the spread of the Al virus, other infectious agents and may facilitate zoonosis.

It was also observed in the various live bird markets that the local chickens were mixed with commercial chickens and other species of birds before or after being purchased from a local seller. This has grave implications for interspecies transmission for avian influenza. 
In this study, the detection of antibodies to low pathogenic avian influenza serotype $\mathrm{A} / \mathrm{H} 9$ in local chickens indicates the presence of low pathogenic AlVs infection. Other subtypes causing highly pathogenic (HP) Avian Influenza particularly subtype $\mathrm{H} 5$ have often been reported in the study area and indeed Nigeria by previous researchers (Ameji et al., 2020). The findings of this research indicate the first report of the detection of $\mathrm{H} 9$ from local chickens in Jos Plateau after a deductive literature search. This finding is of public health significance because of the threat this virus poses to the poultry industry, economy and human health particularly as they can lead to the emergence of reassortant pathogenic strain through co-circulation with other subtypes.

Due to the migratory activities of wild birds, there is a risk of dissemination of avian pathogens into the environment which may have been contracted by resident wild birds and local fowls that are extensively reared in the area. It was observed in the LBMs that both wild and domestic birds were housed together in cages, this promotes the spread of both the HPAI and LPAI virus, these findings agree with Akanbi et al. (2016a), it was also observed that some of these birds were housed or kept in very close proximity with other animals, such as goats, pigs, rams and cows.

Specifically, the avian influenza virus has continued to be a problem worldwide as it can spread rapidly and cause disease in domestic poultry, and some may also infect other animal hosts, including humans. Moreover, Subtain et al. (2011) noted that the first sign of LPAI infection in domestic poultry is often seroconversion which may be the only evidence of infection with some LPAI subtypes. The detection of antibodies to LPAIV H9 and H7 in apparently healthy local chickens in this study indicates that LPAI H9 and $\mathrm{H} 7$ virus subtypes presently circulate in local chickens in Jos-North and Jos-South. This study also conforms to observations by Chinyere et al. (2020) who earlier detected serotype $\mathrm{H} 7$ in Jos LBMs.

Since the vaccination against $\mathrm{Al}$ is not officially permitted in Nigeria and local chickens are not usually vaccinated, according to the report Meseko et al. (2020), the antibodies detected in these birds could only have resulted from seroconversion following natural infection with the viruses. Thus, the local chickens could serve as reservoirs shedding the virus into the environment, thereby playing a crucial role in the epidemiology of the disease which agrees with research carried out by Ameji et al. (2020). This finding is also consistent with previous reports of infection with LPAI H5N8 in Jos Plateau State, Nigeria (Ameji et al., 2019) and other parts of the world such as China, Asia and Europe. The detection of antibodies to both $\mathrm{H} 9$ and $\mathrm{H} 7$ LPAl viruses in some local chickens in this study is of public health concern because co-infection with different avian influenza viruses might provide the opportunity for reassortment, leading to the emergence of novel reassortant subtypes with zoonotic potential. It has been reported previously that if a field virus such as $\mathrm{Al}$ is a low pathogenic type, there is a risk of it mutating to a highly pathogenic form after circulating in susceptible poultry (Richard et al., 2017).

It is important to note that 12 of the ELISA-positive sera were negative for antibodies to $\mathrm{H} 5, \mathrm{H} 7$ and $\mathrm{H} 9$ serotypes LPAI virus, suggesting the possibility of other AIV subtypes circulating among local birds in the study area. There is therefore a need to further investigate the presence of other AIV strains present in local chickens in Jos, Nigeria using a large panel of reference AIV subtypes ( $\mathrm{H} 1-\mathrm{H} 18)$ sera as well as virus isolation and molecular identification techniques such as reverse transcriptase-polymerase chain, reaction (RT-PCR).

The detection of a higher level of seropositivity to LPAI H9 virus in this study compared to the $\mathrm{H} 7$ subtype is significant because, unlike aquatic birds, local chickens are not natural hosts of H9 subtype influenza virus and $\mathrm{H} 9$ infected poultry are asymptomatic (Meseko et al., 2018b; Ameji et al., 2019). This suggests a need to determine the current status of $\mathrm{H} 9$ in the country. Moreover, it is known that normal asymptomatic infection of avian species can silently maintain and transmit influenza virus provided there is an opportunity for genetic reassortment with other prevalent strains (e.g H5) in the avian population and this may be promoted where different avian species are kept together as we observed in these LBMs.

Thus, mixed farming of several species of birds and other livestock practised in many areas of Nigeria reported by Oluwayelu et al. (2015) is a critical management risk that should be discouraged because pigs have also been implicated to be a major mixing vessel for AIV as suggested by (Meseko et al., 2018b). It is important to note that also, local birds have been implicated as incubating vessels for generating influenza reassortants of human and avian origin in the field (Kapczynski, 2009). Additional studies are advocated to determine the potential role of local chickens in the zoonosis of AIV strains in Nigeria.

In this study, it was observed that the local chickens could have been exposed to the virus while scavenging for food. According to Meseko et al. (2018a), most evidence obtained on the prevalence 
of influenza in different types of poultry and from different geographical locations supports the view that the primary introduction is from wild and feral birds. Therefore, influenza viruses are most likely to infect poultry reared in a way that allows contact with feral birds, such as on range poultry farms.

The findings of this study revealed likely circulation of LPAI H9 and H7 viruses in local birds within Jos-North and Jos-South of Plateau State, Nigeria. This study emphasizes the importance of routine surveillance for AIVs in different avian species for the prevention of Al outbreaks in the country. Live Bird Market operators need to be educated on the dangers of collecting, mixing and trading different avian species without biosecurity. The outcome of this research if taken seriously by the governing bodies will help eliminate market practices that can enhance the spread or interspecies transmission of AIVs in the country. The use of social network and market value chain analyses for future Al surveillance investigations is proposed for the development of more effective Al control strategies.

\section{Acknowledgement}

The technical assistance of Drs CN Chinyere and AA Jolly as well as Mr Muyiwa Oyekan of the Animal Influenza Division, National Veterinary Research Institute (NVRI), Vom, are highly appreciated.

Sincere appreciation to Friedrich-Loeffler-Institut, Island of Riems, Germany, for the provision of IDEXX ELISA test kit for the detection of antibody to influenza A virus in animal serum.

\section{Conflict of Interest}

The authors declare that there is no conflict of interest.

\section{References}

Akanbi OB, Ekong PS, Odita Cl \& Taiwo VO (2016a). The effect of highly pathogenic avian influenza (HPAI) H5N1 outbreaks on mixed species poultry farms in Nigeria. Journal of World's Poultry Research, 6(3): 147-152.

Akanbi OB, Meseko CA, Odita Cl, Shittu I, Rimfa AG, Ugbe D, Pam L, Gado DA, Olawuyi KA, Mohammed SB, Kyauta II, Bankole NO, Ndahi W, Joannis TM, Ahmed MS, Okewole PA \& Shamaki D (2016b). Epidemiology and clinicopathological manifestation of resurgent highly pathogenic avian influenza (H5N1) virus in Nigeria, 2015. Nigerian Veterinary Journal, 37(3): 175-186.
Akkermans J, Brenninkmeijer V, Schaufeli W B \& Blonk RWB (2015). Effectiveness of a career development intervention for young employees. Human Resource Management, 54(4): 533-551.

Ameji N, Oladele OO, Bamaiyi PH \& Lombin LH (2020). Clinicopathological features and management of aspergillosis in some poultry farms in Jos metropolis, Nigeria. Sokoto Journal of Veterinary Sciences, doi.10.4314/sokjvs.v18i4.8.

Ameji NO, Oladele OO, Meseko CA, Mshelia GD \& Lombin LH (2019). Outbreak of highly pathogenic avian influenza subtype H5N8 in two multi-age chicken farms in Jos, Plateau State, Nigeria. Journal of Veterinary Sciences, 17(3): 60-65.

Ameji NO, Sa'idu L \& Abdu PA (2017). Detection of avian influenza antibodies and antigens in poultry and some wild birds in Kogi State, Nigeria. Sokoto Journal of Veterinary Sciences, 15(3):62-68.

Bevins SN, Dusek RJ, White CL, Gidlewski T, Bodenstein B, Mansfield KG, Debruyn P, Kraege $D$, Rowan $E$, Gillin C, Thomas $B$, Chandler S, Baroch J, Schmit B, Grady MJ, Miller RS, Drew ML, Stopak S, Zscheile B, Bennett J, Sengl J, Brady, Caroline, Ip HS, Spackman E, Killian ML, Torchetti MK, Sleeman JM \& Deliberto TJ (2016). Widespread detection of highly pathogenic $\mathrm{H} 5$ influenza viruses in wild birds from the Pacific Flyway of the United States. Scientific Reports, doi.10.1038/srep28980

Chinyere CN, Okwor EC, Meseko CA, Ezema WS, Choji ND, Amos DI, Sulaiman LK, Shittu I \& Nwosuh $C$ (2020). Sero-detection of avian influenza $\mathrm{A} / \mathrm{H7}$ in Nigerian live-bird markets in Plateau State. Nigerian Veterinary Journal, 41(2): 161-174.

Cohen J (1988). Statistical Power Analysis for the Behavioural Science, second edition. Department of Psychology New York University New York, New York. Lawrence Erlbaum Associates, Publishers. Pp 50- 52.

Kapczynski A (2009). Commentary: Innovation policy for a new era. Journal of Law, Medicine and Ethics, doi.10.1111/j.1748720X.2009.00370.x.

Kumar B, Asha K, Khanna M, Ronsard L, Meseko CA \& Sanicas M (2018). The emerging influenza virus threat: Status and new prospects for its 
therapy and control. Archives of Virology, 41(2): 831-844.

Lamb RA \& Roberts KL (2014). Influenza (MS 654) In Reference Module in Biomedical Sciences. Encyclopedia of Virology, doi.10.1016/b9780-12-801238-3.02606-4

Machalaba CC, Elwood SE, Forcella S, Smith KM, Hamilton K, Jebara KB, Swayne DE, Webby RJ, Mumford E, Mazet JA, Gaidet N, Daszak P \& Karesh WB (2015). Global avian influenza surveillance in wild birds: A strategy to capture viral diversity. Emerging Infectious Diseases, doi.10.3201/eid2104.141415.

Markets B, Chowdhury S, Azziz-baumgartner E, Kile JC, Hoque A, Rahman MZ, Hossain E, Ghosh PK, Ahmed SS, Kennedy ED, Sturm-ramirez K \& Gurley ES (2020). Association of biosecurity and hygiene practices with environmental contamination with influenza a viruses in live bird markets, Bangladesh. Emerging Infectious Diseases, 26(9): 2087 2096.

Meseko CA \& Oluwayelu DO (2019). Avian influenza. Transboundary Animal Diseases in Sahelian Africa and Connected Regions, doi.10.1007/978-3-030-25385-1_17.

Meseko CA, Ehizibolo D \& Vakuru C (2018a). Migratory waterfowls from europe as potential source of highly pathogenic avian influenza infection to Nigeria poultry. Nigerian Veterinary Journal, 39(1): 1-15.

Meseko C, Globig A, ljomanta J, Joannis T, Nwosuh C, Shamaki D, Harder T, Hoffman D, Pohlmann $A$, Beer $M$, Mettenleiter $T$ \& Starick $E$ (2018b). Evidence of exposure of domestic pigs to highly pathogenic avian influenza H5N1 in Nigeria. Scientific Reports, doi.10.1038/s41598-018-24371-6.

Meseko CA, Shittu Al \& Akinyede O (2012). Seroprevalence of fowl pox antibody in indigenous chickens in Jos north and south council areas of Plateau State, Nigeria: Implication for vector vaccine. ISRN Veterinary Science, doi.10.5402/2012/154971.

Meseko CA, Olorunsola B, Chinyere CA, Olawuyi K, Ijomanta J, Haruna AM \& Asala O (2020). Recurrent epizootics of highly pathogenic avian influenza in Nigeria. Nigerian Veterinary Journal, 41(2): 7-17.

Office International des Epizooties (2018). Avian influenza: Infection with avian influenza viruses. OIE Terrestrial Manual. Pp 829-831.

Oluwayelu DO, Aiki-Raji O, Adigun OT, Olofintuyi OK \& Adebiyi Al (2015). Serological survey for avian influenza in turkeys in three states of southwest Nigeria. Influenza Research and Treatment, doi.10.1155/2015/787890.

Payne S (2017). Family Orthomyxoviridae. In: Viruses, doi.10.1016/b978-0-12-803109-4.00023-4.

Richard M, Fouchier R, Monne I \& Kuiken T (2017). Mechanisms and risk factors for mutation from low to highly pathogenic avian influenza virus. EFSA Supporting Publications, doi.10.2903/sp.efsa.2017.en1287

Steensels D, Oris E, Coninx L, Nuyens D, Delforge ML, Vermeersch P \& Heylen L (2020). Hospitalwide SARS-CoV-2 antibody screening in 3056 staff in a tertiary center in Belgium. Journal of the American Medical Association, 324(2): 195-197.

Subtain SM, Chaudhry ZI, Anjum AA, Maqbool A \& Sadique $U$ (2011). Study on pathogenesis of low pathogenic avian influenza virus $\mathrm{H} 9$ in broiler chickens. Pakistan Journal of Zoology, 43(5): 999-1008.

Thomas PG, Shubina, M \& Balachandran S (2019). National Library of Medicine. ZBP1/DAIDependent Cell Death Pathways in Influenza A Virus Immunity and Pathogenesis, doi.10.1007/82_2019_190.

Tindale LC, Baticados W, Duan J, Coombe M, Jassem A, Tang $P$, Uyaguari-Diaz $M$, Moore $R$, Himsworth C, Hsiao W \& Prystajecky N (2020). Extraction and detection of avian influenza virus from wetland sediment using enrichment-based targeted resequencing. Frontiers in Veterinary Science, doi.10.3389/fvets.2020.00301.

World Health Organization (2019). Institutional repository for information sharing: Weekly Epidemiological Record. Review of the 2018-2019 influenza season in the northern hemisphere. doi.who.int/iris/handle/10665/326244. 